\title{
A TRÍADE IDENTIDADE, ÉTICA E INFORMAÇÃO NA BIBLIOTECONOMIA BRASILEIRA: ANÁLISE SOBRE O CÓDIGO DE ÉTICA DO BIBLIOTECÁRIO
}

\author{
Jonathas Luiz Carvalho Silva
}

\section{Resumo:}

Aborda as possibilidades de estabelecimento da relação entre os termos identidade, ética e informação atestando a observância da configuração de uma identidade da ética que possa influir no comportamento informacional dos profissionais e usuários. Considera a ética como um pressuposto filosófico e político que deve estar relacionado aos fatos cotidianos para poder desenvolver estudos mais efetivos acerca do comportamento moral da humanidade. Para tanto, atesta a importância da ética historicista a fim de conceber uma concepção mais precisa sobre o termo em questão. Estabelece como condição problematológica os seguintes questionamentos: o código de ética do bibliotecário é bem elaborado? Quais são as suas deficiências e pontos qualitativos do documento? O código de ética tem sido cumprido pela categoria biblioteconômica? Analisa o código de ética do bibliotecário considerando todos os pontos que o constituem, suas deficiências e qualidades, bem como aponta sugestões para o aprimoramento do código, além de verificar que as reflexões expostas possibilitam inferir que, no caso de analisar atitudes não condizentes com a dignidade da profissão, seria mais adequado uma Comissão de Ética constituída para avaliar ações que aparentemente não se enquadrem num Código de Conduta Profissional do que um Código de Ética com prescrições para fixar normas de conduta. Aponta finalmente que é preciso uma reformulação do código e que muito do que se tem apregoado não tem sido cumprido nas práticas profissionais e cotidianas do bibliotecário.

\section{Palavras-chave:}

Ética. Identidade; Informação; Código de ética do bibliotecário; Biblioteconomia.

\section{THE TRIAD IDENTITY, INFORMATION AND ETHICS IN BRAZILIAN LIBRARIANSHIP: ANALYSIS OF THE LIBRARIAN CODE OF ETHICS}

\begin{abstract}
:
Discusses the possibilities of establishing the relationship among the terms identity, ethics and information observing the configuration of ethics identity that can influence the behavior of information professionals and users. It considers the ethic as a philosophical and political condition that must be related to everyday events, in order to develop a more effective research on the moral behavior of mankind. To do so, certifies the importance of historicist ethics to devise a more accurate meaning for the term in question. It poses as the problem the following questions: the librarian code of ethics is well prepared? What are the weaknesses and qualitative points of the document? The code of ethics has been followed by the librarian's category? It examines the librarian code of ethics considering all the qualities and weaknesses, and make suggestions for improving it. It also verify if the above considerations permit to infer that if attitudes do not look consistent with the dignity of the profession it would be more appropriate to be submitted to an Ethics Committee - established to assess actions that apparently did not fit in a Code of Professional Conduct as an Ethics Code, with requirements for setting standards of conduct. Finally suggests that the code need to be reformulated and much of what has been proclaimed has not been fulfilled in everyday work practices of the librarian.
\end{abstract}

\section{Keywords:}

Ethics; Identity; Information; Librarians Code of ethics; Librarianship 


\section{INTRODUÇÃO}

A ética é, talvez, uma das temáticas mais mencionadas e discutidas na história da humanidade, seja nos meandros da vida cotidiana, mercadológica e/ou acadêmica. Porém, muitas vezes essa menção a ética se torna pejorativa e vaga, pois a utilização do termo decorre em prol de um benefício próprio ou quando a utilização é conveniente para um indivíduo ou grupo político, social e econômico. Concomitante a usual recorrência da palavra ética na sociedade, ocorre uma falta de compreensão ou um entendimento um tanto quanto limitado da temática por parte da população, haja vista que possui uma noção eminentemente científica e ampla.

Associamos a ética, neste trabalho, as noções dos termos identidade e informação como forma de conceber o comportamento informacional e a caracterização identitária deste termo formando uma tríade interdependente a fim de facilitar a compreensão daquilo que tanto se denomina ética. Para dar uma consistência e aplicabilidade aos três assuntos supramencionados atribuímos como ponto de análise e objeto deste artigo, o código de ética do bibliotecário no Brasil, considerando as suas implicações técnicas, jurídicas, sociais, políticas e de modo mais geral profissionais. Assim, estabelecemos como condição problematológica do presente trabalho os seguintes questionamentos: o código de ética do bibliotecário é bem elaborado? Quais são as suas deficiências e pontos qualitativos do documento?

Percebemos, dessa forma, a necessidade inicial de saber a qualidade da legislação deste código de ética, visando saber posteriormente o nível de cumprimento do material. Discutindo estas questões esperamos conhecer um pouco mais acerca do caráter informacional da legislação bibliotecária e da identidade do profissional a partir dessa questão burocrático-jurídica.

A discussão tem seu início a partir de uma breve análise sobre a ética levando em consideração pontos como a definição, o campo e o objeto da temática, visto que são pontos bastante passíveis de discussão e compreensão pela sociedade. A definição de ética se torna algo premente a partir do momento em que precisamos saber a significação deste assunto e quais termos o caracterizam para que, em seguida, possamos conhecer melhor o seu campo de estudo considerando a sua cientificidade e verificar finalmente do 
que trata a ética, isto é, qual o seu objeto de estudo. Em seguida invoca a discussão acerca da tríade ética-identidade-informação, visando conceber as relações e contribuições que a junção destes termos pode oferecer, bem como as suas diferenciações e peculiaridades como forma de entender a funcionalidade da identidade e subsídio informacional da ética para as diversas áreas do conhecimento e da sociedade. Adiante, aborda o código de ética do bibliotecário no Brasil atestando a observância de sua estrutura conteudística, suas condições jurídicas, burocráticas e de aplicabilidade profissional. O debate sobre o código de ética de uma determinada área do conhecimento se torna importante a partir do momento em que ele é o norteador da área e a sua qualidade profissional depende bastante, tanto da qualidade do código, como da boa aplicabilidade do documento que rege um grupo específico. É preciso também desmistificar algumas presunções terminológicas em que os termos código de ética e código de conduta profissional diferem em seu caráter filosófico e jurídico.

\section{DA NOÇÃO DE ÉTICA: QUESTÕES PRELIMINARES RELACIONADAS AO CARÁTER SEMÂNTICO, AO OBJETO E CAMPO DE ESTUDO}

A ética ganhou uma complexidade muito grande na história da humanidade, haja vista o seu longo percurso que vem desde a antiguidade grega, tendo como referenciais os filósofos Sócrates, Platão e, especialmente, Aristóteles, além dos sofistas ${ }^{1}$. Na idade Média há a constituição de uma nova roupagem da ética, adaptada as idéias de Platão e Aristóteles voltada para o processo de cristianização, tendo como baluartes o estudioso Santo Agostinho (354-430) e Santo Tomás de Aquino (1226-1274)². A idéia de Platão em que o homem deveria purificar a sua alma a fim de estabelecer a sua libertação e a reconstituição de suas idéias é adaptada por Santo Agostinho na elevação a Deus e sua imagem pura e libertadora. Aristóteles já tinha como preceito ético a condição teleológica da felicidade (eudaimonia) que seria guiada pela razão e a contemplação do conhecimento equilibrado e desenvolvido pela coerência e Tomás de Aquino considerava

\footnotetext{
${ }^{1}$ Os sofistas constituíram o movimento intelectual que se deu no século V (A. C.) e que desde Platão e Aristóteles, aproximadamente no século IV (A. C.), ganhou uma forma bem pejorativa de ser caracterizada. Originariamente sofista quer dizer aquele que é mestre ou sábio identificando sua relação com o termo sofia (sabedoria). Porém, em virtude do posicionamento atuante e autônomo dos sofistas que ensinavam a arte de convencer através da retórica duvidando de tudo aquilo que fosse previamente ou cientificamente estabelecido como verdade é que muitos estudiosos contemporâneos e que vivenciaram o movimento conceberam grande antipatia as idéias dos mestres sofistas.

${ }^{2}$ Reiterando que a ética religiosa da idade média não é considerada por muitos estudiosos como uma filosofia, mas como uma percepção cristã da realidade religiosa, social e política do período que durou aproximadamente mil anos. Mas não podemos negar que a base das éticas cristãs agostiniana e tomista se valiam de pressupostos filosóficos, especialmente em suas perspectivas de desenvolvimento, mas se diferenciavam no seu processo teleológico.
} 
que Deus seria o bem ou fim supremo, que efetiva a felicidade na vida do ser humano o que diferenciava da idéia do filósofo grego, mas ambas as idéias se assemelhavam a partir do momento em que a ética tomista afirmava que o conhecimento era a chave para se chegar neste bem supremo, ou seja, eles discordavam na caracterização teleológica de indicação ética, mas convergiam no meio para se chegar a finalidade do processo. (VASQUEZ, 1987).

Já na Idade Moderna temos um rompimento das idéias de ética com os preceitos do período medieval em que antes se pensava a ética numa tessitura eminentemente teocêntrica passando a pensá-la como um procedimento antropocêntrico ${ }^{3}$. Podemos destacar no período moderno as idéias ética de Descartes, no século XVII e de Kant no século XVIII em que este último procedeu uma ética formal baseada na idéia de boa vontade como indicativo da constituição do fato da moralidade e do conhecimento humano. A ética kantiana, talvez, seja o modelo mais convincente do período moderno, que seja discutido e respeitado no período atual por tratar o homem como um instrumento ontológico político, criativo e autônomo. ${ }^{4}$

A ética contemporânea pode ser considerada a mais complexa e diversificada da história da humanidade em virtude das diversas idéias propaladas pelos estudiosos e de diferentes propostas científicas e metodológicas. Podemos destacar estudiosos como Marx, os filósofos do existencialismo, como Kierkegaard, Max Stirner e Sartre, além do Neopositivismo e da Filosofia Analítica. A corrente marxiana faz uma crítica aos valores morais do passado e constitui a apresentação de novas proposições morais, enquanto a corrente existencialista pode ser considera um pouco fragmentada, dado que os dois primeiros estudiosos atestam a idéia de uma ética individualista e irracionalista partindo da idéia de um ser superior como o valor supremo de um bem ético que sustenta as relações pessoais, enquanto Sartre se destaca pelo seu ateísmo e pela coletividade das relações pessoais atribuindo a noção ontológica de que o homem é liberdade. Já os

\footnotetext{
${ }^{3}$ A mentalidade do período moderno se dá pelo pensamento mais autônomo do ser humano em detrimento do que se pregava na Idade Média a noção do ser humano submisso a imagem de Deus. As idéias e os questionamentos da sociedade moderna começavam a se aflorar de tal forma que o homem aprecia como centro do processo político, cultural e moral da sociedade.

${ }^{4}$ Ressaltando que a boa vontade pregada por Kant tinha como pressuposto uma ação consciente do ser humano respeitando as leis e os princípios morais que devem ser seguidos em qualquer tempo e condição. Porém, essa boa vontade não pode ser encontrada em si mesma, mas na vontade e/ou intenção com que se fez. Por isso, a noção da ética kantiana é bastante formal e imperativa e também muito difícil de ser seguida, mas interessante para ser estudada e compreendida. (KANT, 2003).
} 
filósofos analíticos tentam fazer um arrazoado da história da ética a fim de desenvolver uma análise sobre a linguagem moral dos diversos períodos para se conhecer a linguagem moral presente na sociedade contemporânea. (VASQUEZ, 1987).

O pensamento da ética contemporânea nos servirá de instrumento conteudístico para entendermos a configuração semântica, bem como o campo e objeto de estudos da ética. O que fizemos nos parágrafos anteriores não foi uma análise histórica, mas apenas uma descrição cronológica para compreender a diversidade do pensamento ético e suas diferentes formas de compreensão. Partindo dos pressupostos éticos que acompanhamos nos diversos períodos históricos entendemos que conceber uma definição de ética não é uma tarefa nada fácil e bastante inglória, especialmente quando se quer afirmar imperiosamente o significado do termo em questão. Ao mesmo tempo, não podemos nos furtar de estruturar uma definição que caracterize a linhagem do presente trabalho no tocante a concepção de ética.

Dessa forma, consideramos conveniente buscar em Aristóteles (2002, p. 40) uma noção de ética, haja vista ter sido este um dos primeiros e mais expressivos estudiosos da história da ciência a formular uma idéia tão embasada sobre o assunto. Assim diz o filósofo grego:

Seria, assim, de se concordar ter que ser ele o objeto da ciência, entre todas, de maior autoridade - uma ciência que fosse, preeminentemente, a ciência maior. E parece ser esta a ciência política, ${ }^{5}$ posto que é ela que determina quais ciências devem existir nos Estados e quais ramos do conhecimento deve cada diferente classe de cidadãos aprender e até que ponto; e observamos que mesmo as mais altamente consideradas das capacidades, tais como a estratégia, a economia doméstica, a oratória se acham subordinadas à ciência política.

Diante da fala de Aristóteles podemos perceber que a ética é considerada auxiliar da ciência maior, ou seja, a ciência política. Sendo a ética uma das ciências que vai estimular no indivíduo um processo de atuação e posicionamento do ser humano a partir da noção de ação e bem, a política ganha um respaldo. Por isso, o primeiro questionamento que podemos fazer em torno de uma definição de ética é que se configura numa ciência que estuda a caracterização da ação humana. A cientificidade da ética permite inferir que deve ser estudada com rigor, de modo investigativo e fundamentado, visando o seu

\footnotetext{
${ }^{5}$ Ao que parece Aristóteles não fala sobre ética nesta citação, mas na verdade a visão do filósofo é de que a ética, trata da ação e do bem no contexto indivíduo, mas é considerada como uma ciência prática auxiliar a política, a ciência prática maior. Isto quer dizer que a partir do momento em que o ser humano possui uma configuração ontologicamente política este é atribuído como objeto diretamente da política e não da ética, o que não é um menosprezo ao termo tratado neste capítulo, mas que está contida na ciência política.
}

(c) Revista Digital de Biblioteconomia e Ciência da Informação,Campinas, v.7, n. 2, p. 76-101, jan./jun. 2010- ISSN: 1678-765X. 
reconhecimento como uma ciência política e diretamente associada a filosofia. Para ampliar o questionamento da citação apresentada, aferindo a noção mais contemporânea do termo, podemos incluir a noção de caracterização da ação humana através do comportamento moral do indivíduo, uma vez que a ação política do indivíduo deve seguir alguns pressupostos morais que impliquem em uma ação consciente e de bondade. Atribuindo a fala de Vasquez (1987, p. 12) diz que "ética é a teoria ou ciência do comportamento moral dos homens em sociedade. Ou seja, é a ciência de uma forma específica do comportamento humano”.

Podemos afirmar que a ética é a ciência da moral, mas esta abordagem científica dos problemas morais ainda é muito incipiente e insatisfatória. Talvez, por isso, a ética tenha se tornado tão pejorativa e seja falada de forma tão vaga, superficial e sem um sentido mais firme. Agora, obviamente que essa não contemplação da ética no estudo da moral também perpassa pelos diversos problemas sociais, políticos, econômicos e culturais que norteiam e dão uma grande crise de sentido a sociedade fazendo com que os indivíduos tentem criar seus próprios valores e normas de conduta.

Especificando ainda outra definição de ética, inserimos Hegel (1997), quando afirma que este termo pressupõe a realização do conceito de consciência-de-si, que exige que uma consciência abandone uma postura isolada para se relacionar com os outros, visando estabelecer uma coletividade mais concreta. Isto quer dizer que a ética, para conceber noção de aplicabilidade ou de um sentido mais consistente, precisa estar relacionada a vida do indivíduo, de grupos e, principalmente, da sociedade. Neste contexto já temos uma relação direta entre ética e identidade em que ambos possuem uma caracterização individual que é a consciência-de-si, mas que para conquistar um sentido mais concreto necessitam de relações com outros indivíduos e grupos. É o que podemos chamar na teoria identitária de marcas essencialistas e não-essencialistas, isto é, a primeira remete a características genuínas de um indivíduo e a segunda a um processo adquirido através das relações sociais envidada pelos indivíduos. (SILVA, 2000). Assim, a ética também precisa de suas concepções essencialistas e não-essencialistas para conquistar uma posição mais concreta, mas é preciso que a consciência-de-si seja interativa e autônoma para estabelecer essas marcas éticas.

(c) Revista Digital de Biblioteconomia e Ciência da Informação,Campinas, v.7, n. 2, p. 76-101, jan./jun. 2010- ISSN: 1678-765X. 
Partindo do conceito de ética é possível identificar com certa facilidade o seu objeto: a moral. Então relacionando o conceito ao objeto da ética é pertinente interpelar: qual a diferença entre ética e moral? A primeira e principal diferença entre os termos é que o primeiro faz parte de uma proposição científica, enquanto o segundo não apresenta esse caráter. Mas fica a pergunta: será que nada relacionado a idéia do mundo e do comportamento moral pode ser científico? O único momento em que a moral pode ser tratada como científica é quando se trata de um conhecimento moral epistemológico. Inclusive pelo fato de que a ética serve justamente para estudar cientificamente o caráter da moral.

A moral se configura comumente em problemas e situações práticas que podem ou não ser resolvidas de acordo com o pensamento de cada indivíduo. O fato é que o indivíduo pode conceber um valor a uma determinada ação que seja contrária aos juízos e normas estabelecidos. Por exemplo, uma pessoa comete um crime e o seu amigo sabe do ocorrido. Deve o amigo denunciar o outro seguindo os preceitos jurídicos das normas ou deve se valer da amizade e omitir o acontecimento? Ora, se o indivíduo denuncia o seu amigo, isso implica dizer que o seu comportamento está voltado para os interesses da nação em detrimento da amizade até então existente.

A afirmação do parágrafo anterior mostra que a noção ontológica do comportamento moral do indivíduo é bastante complexa e diversificada, de acordo com o caráter e situação do indivíduo. Por isso, o ser humano cria diversos valores morais para desenvolver sua vida cotidiana, mesmo que em alguns pontos, esteja diferente daquilo que comumente é estabelecido como norma e preceito a ser cumprido. A ética pode até fornecer ao indivíduo a melhor forma de agir de acordo com os preceitos e normas, mas não dirá necessariamente como o ser humano deve agir. Em virtude da elaboração de inúmeras idéias sobre ética fica mais complicado ainda fornecer um direcionamento mais preciso sobre as perspectivas comportamentais relativas a moral, haja vista que cada ser humano aproveitará a noção de “ética” que for mais conveniente para a resolução dos seus problemas prático-morais.

Então, podemos inferir que a definição e o objeto da ética estão intrinsecamente concatenados, haja vista que em ambos a fala principal é uma só: o comportamento moral do indivíduo. A diferença é que a definição de ética envolve outros atributos como a 
noção politico-filósofica, além de sua cientificidade, enquanto o objeto de estudo se resume a concepção moral do indivíduo. E qual seria o campo de estudo da ética? Devemos entender aqui que o objeto de estudo de uma determinada área do conhecimento implica na concepção de uma ou mais terminologias que devem ser estudadas cientificamente, enquanto o campo de estudo se caracteriza pela reunião dos fatores e os procedimentos metodológicos que irão envolver o estudo do objeto e de outros fatores científicos dessa área. O campo de estudo pode arrolar a reunião de ciências para a explicação e estudo de um determinado objeto ou simplesmente a organização conteudística e metodológica desse objeto.

Identificar um campo não parece ser uma tarefa fácil, especialmente quando se leva em consideração a amplitude da ciência que está sendo abordada. No caso da ética entendemos que o seu campo de estudo fica mais fácil de ser delimitado após a compreensão do conceito e do objeto do termo. De acordo com Vasquez (1987) o campo da ética é uma teoria investigativa que visa à explicação ou resolução de um tipo de experiência ou comportamento moral dos homens considerando a sua totalidade, diversidade e variedade.

Por isso a ética objetiva dar uma explicação mais sólida para os problemas cotidianos prático-morais a partir de uma tendência mais firme e constante e não fornecer variações de idéias de acordo com as conveniências do indivíduo, mas sim da sociedade, ou seja, de uma coletividade. Isso significa dizer que a ética estrutura comportamentos gerais de como agir e se posicionar, enquanto a ação moral humana se vale da conveniência da cada indivíduo. Mas não devemos considerar a ética como uma norma ou um conjunto de recomendações, mas sim como um estudo científico e investigativo que visa explicar de forma geral o fenômeno da moral.

Portanto, podemos afirmar que a ética passa a ter um sentido mais sólido, pelo menos teoricamente, quando se entende a sua definição, o seu objeto e campo de estudo, além de exemplos relacionados a diferenciação e relação entre ética e moral. Para compreendermos melhor a significação da ética relacionamos o termo retromencionado a identidade e informação, como forma de entender um pouco a identidade da ética e o seu comportamento informacional que será abordado a seguir.

(c) Revista Digital de Biblioteconomia e Ciência da Informação,Campinas, v.7, n. 2, p. 76-101, jan./jun. 2010- ISSN: 1678-765X. 


\section{A TRÍADE ÉTICA-IDENTIDADE-INFORMAÇÃO}

Como relatamos no capítulo anterior a ética possui grande complexidade, mas tem se apresentado bastante confusa, tanto aos olhos de muitos estudiosos, como à sociedade global. Dessa forma, entendemos ser importante associar a ética às temáticas da identidade para caracterizar a sua essência e os seus indícios informacionais de forma a constatar sua percepção pela população global. Entendemos não ser uma tarefa fácil fazer uma constituição da identidade da ética, porém, esta necessidade é premente diante do turbilhão de conteúdos lançados sobre a ética no transcorrer histórico. Obviamente que não temos apenas uma maneira de fazer a caracterização identitária da ética, assim como não seria com outro objeto de estudo, vez que podemos estender uma concepção identitária de um dado objeto sob diversas óticas e perspectivas, mas ao mesmo tempo é preciso elencar uma forma mais eficiente e eficaz de conceber esta identificação.

Inicialmente, acreditamos que a associação da ética ao processo de caracterização identitária se dá principalmente pela suas correntes. Ora, as correntes da ética em sua diversidade, variedade e complexidade determinam a sua atuação no seio do comportamento moral e da sociedade, o que nos faz crer que a partir daí seria mais visível notificar as suas concepções identitárias. Neste caso, estaremos destacando a corrente da ética historicista como forma de explicar as possibilidades de atuação sócio-moral e cotidiana.

Porém, antes de iniciar com a corrente historicista da ética consideramos conveniente mencionar três tipos básicos de caracterização identitária em que a ética está envolvida: a identidade histórica, a identidade ameaçada e a identidade modificada. (BOGO, 2008). O primeiro tipo de identidade envolve a ética no que se refere a sua construção num longo processo cronológico da humanidade que vem desde a antiguidade até os dias atuais, mas que possui diversas variações ocasionando a estruturação de diferentes tipos de noções éticas nesse decorrer histórico e dificultando a compreensão sobre a sua essência. O segundo tipo de identidade pode ser verificado a partir do tom pejorativo e pouco compreensível com que tem sido tratada a ética na sociedade, especialmente em nossos dias. A falta de uma definição mais precisa e aplicativa tornam a ética um termo semanticamente vago e que pode ser utilizado de qualquer modo e em qualquer circunstância, seja ela pessoal, familiar, profissional, religiosa, enfim, nos mais diversos 
aspectos da vida cotidiana. Agora de onde vem essa ameaça a uma proposição mais consistente a respeito da identidade da ética? Podemos afirmar que essa ameaça vem da própria sociedade em seu transcurso histórico com suas desigualdades e arbitrariedades.

Não é a toa que Castells (2002, p. 24) fala que "a construção social da identidade sempre ocorre em um contexto marcado pelo poder”. E as correntes da ética variam, num contexto marcadamente histórico, em diversas perspectivas de adequação ou de resistência a um determinado poder, o que pode ocasionar essa ameaça a identidade da ética, especialmente em virtude da diversidade tipológica que faz com que os indivíduos a utilizem da forma como consideram mais conveniente para a satisfação dos seus interesses ou manutenção do poder.

Com relação a identidade modificada é configurada em diversos tipos de indivíduos e grupos sociais, especialmente em nossos dias, tendo afetado profundamente a compreensão do significado da ética, de modo que a supervalorização dos interesses econômicos e do poder de uma minoria tem influenciado negativamente acerca da noção de uma funcionalidade ética e, por conseguinte, de sua caracterização identitária.

Bogo (2008) é muito feliz quando exemplifica um posicionamento de modificação da identidade quando fala sobre a agricultura que possui (ou possuía) uma identidade histórica mais consistente e nas últimas décadas têm sofrido sérias ameaças e modificações em sua estrutura de atuação. $\mathrm{O}$ autor afirma que há identidades que estão sendo modificadas propositadamente para satisfazer os anseios das empresas que possuem o poder econômico no setor da agricultura, especialmente a questão relativa aos genes que são retirados das espécies e recombinados até serem transportados para outros indivíduos. ${ }^{6}$

Diante desse exemplo podemos perguntar: que posicionamento ético está sendo atribuído as grandes empresas? Será que as supervalorizações do dinheiro e do poder estão além da valorização da vida? Esse exemplo apenas mostra que a identidade da ética tem sido

\footnotetext{
${ }^{6} \mathrm{O}$ autor considera que ultimamente muito se tem falado sobre os alimentos e as sementes transgênicas que através da Biotecnologia que penetra na célula para modificar as suas formações genéticas. Todavia, estão sendo ainda mais ousados e estão analisando e modificando a forma dos átomos, moléculas e partículas que não podem ser vistos, salvo com a utilização de aparelhos especializados. É o que podemos chamar de nanotecnologia. $\mathrm{O}$ fato é que essas alterações transgênicas estão promovendo grandes lucros às empresas de maior porte que, por sua vez, por causa da concorrência, já que não dispõem das sementes transgênicas estão em livre derrocada perdendo os seus negócios e muitas vezes a sua subsistência alimentar.
} 
ameaçada constantemente quando os indivíduos criam seus próprios juízos de valor desenvolvendo os seus comportamentos morais, visando o benefício de uma minoria em detrimento de uma maioria.

Como já dissemos obviamente que a responsabilidade por esses acontecimentos não é do termo ética em si, mas de toda a estrutura econômica e política criada para favorecer aqueles que detêm o poder e se apropriam de diversas condições para lograrem êxito independente das conseqüências que podem ser ocasionadas à sociedade. Mas fica evidente que essa proporção concentrada do poder em “poucas mãos” tem descaracterizado e ameaçado a identidade ética, dando descrédito a uma ciência milenar e que auxilia na explicação de diversos indivíduos e grupos sociais. Mas não podemos deixar de considerar que a ética surge como um paradigma explicativo de determinadas realidades se configurando como um guia. Agora, a ética não possui e não deve possuir um tom arbitrário e coercitivo, muito embora tenha sido atribuída por diversos indivíduos e grupos sociais como algo tendencioso ou que deve ser seguido conforme suas necessidades sem uma preocupação com “o mundo que os rodeia”. (BARROCO, 2008).

Diante dessa associação que fizemos entre identidade e ética considerando suas perspectivas, limitações, além de seus conflitos e processos, acreditamos agora ser pertinente a fala sobre a corrente historicista da ética. Escolhemos esta corrente da ética pelo fato de indicar a concepção ontológica do fazer humano em diversos períodos atribuindo suas peculiaridades, necessidades e procedimento para a sua satisfação. Não podemos deixar de considerar que uma análise historicista nos faz refletir sobre os processos de atuação humana que são compartilhados direta ou indiretamente por gerações diferentes. Por exemplo, os estudos dos grandes cientistas de diversos períodos históricos desde a antiguidade até os dias atuais contribuem diretamente para os rumos da humanidade em que os seres humanos e grupos sociais desenvolvem suas adaptações e constituem novas idéias.

O que isso quer dizer? Simplesmente que a proposição ética não pode jamais se desvincular das questões cotidianas que norteiam a humanidade em seus diversos contextos históricos e societários. Quanto mais a ética se distanciar dos fatos cotidianos em sua concepção histórica estará perdendo qualquer credibilidade e possibilidade de conceber o significado das implicações morais. Obviamente que cada geração tem as suas 
peculiaridades e necessidades específicas, mas há questões implícitas que envolvem todo ou, pelo menos, a maior parte do período histórico da humanidade.

E como os estudos éticos podem permanecer ou adquirir consistência? Além de não se desvincular dos fatos cotidianos, a resposta mais direta é não se distanciar também dos pressupostos filosóficos que norteiam o pensamento humano, pois, embora cada período histórico tenha tido suas peculiaridades, há algumas implicações que perpassam por qualquer período e que a ética através de um estudo filosófico-historicista pode ajudar a explicar. Quem nos explica a afirmação dos dois parágrafos anteriores é o estudioso Georg Lukács (1990, p. 87) quando fala que:

[...] Para a filosofia, a essência e o gênero humano, o seu de-onde e para-onde, constituem o problema central permanente, mesmo se continuamente mudando de acordo com a época histórica. Indo para além da necessária divisão social do trabalho das ciências, a universalidade filosófica autêntica não é nunca uma simples síntese enciclopédica ou pedagógica de resultados comprovados, mas uma sistematização, como meio mais adequado para entender do modo mais adequado possível este de-onde e para-onde do gênero humano.

A filosofia é o pressuposto que dá origem a ética como conhecimento ou como percepção moral, teórica, investigativa e científica. Quando a ética se dá num saber histórico buscando alcançar um contexto mais universal da realidade humana passa a ter mais possibilidades de se voltar para o comportamento moral cotidiano do indivíduo, uma vez que passa a contribuir para a coletivização das ações humanas interferindo no processo de individualização que tanto é latente nas sociedades contemporâneas.

E como a ética pode alcançar essa percepção mais universal? Através dos estudos dos valores que norteiam e nortearam a humanidade nos diferentes períodos históricos. Não estamos afirmando aqui que dessa forma a ética vai resolver os problemas morais cotidianos, mas pode adquirir maior consistência, credibilidade e influência no processo de ação social dos indivíduos. Conhecer a história e os valores da humanidade é de grande importância para poder explicar e orientar o comportamento moral das sociedades fazendo com que a ética conquiste uma identidade mais sólida e deixando de estar relacionada a uma identidade modificada em torno da valorização do individualismo humano em detrimento do coletivo e da identidade ameaçada. Barroco (2008, p. 84) coloca a importância de uma ética baseada em processos sócio-históricos quando afirma que: 
Uma ética configurada como reflexão crítica e sistematização teórica orientada por pressupostos sócio-históricos e dirigida a valores emancipatórios é consciente de seus limites objetivos na sociedade burguesa, mas pode contribuir para a ampliação de uma consciência social crítica. Como conhecimento crítico, pode contribuir para o desvelamento da moral dominante, de suas contradições, das normas abstratas, da coisificação das motivações éticas, no sentido de identificar os fundamentos históricos da alienação moral e apontar estratégias de enfrentamento ético-político das condições adversas do presente, orientadas por uma projeção do amanhã.

A autora menciona que a ética para ser efetivamente consistente precisa ser estudada e entendida pelos seus estudiosos através de uma relação com as questões sociais, políticas, econômicas, culturais, educacionais e de outras esferas da vida humana para conceber e explicar os fenômenos morais. Ou seja, entender o comportamento moral é um indício ontológico de outras conjunturas da humanidade. Os estudos éticos precisam compreender as contradições existentes na sociedade, suas desigualdades e deficiências para que possa inserir uma contribuição mais conscientizadora para os rumos da sociedade global.

Dessa maneira entendemos que a identidade da ética tem se configurado em tendências variadas e algumas vezes confusas que podem influenciar no agir humano. Novamente utilizando Castells (2002) quando acrescenta ainda três tipos de identidade: legitimadora, de resistência e de projeto. Atentamos para esta última que significa o posicionamento dos atores sociais que buscam construir uma nova identidade a fim de promover um novo posicionamento na sociedade e modificações na estrutura social.

Entendemos que uma identidade da ética na contemporaneidade tem atuado nos três momentos identitários caracterizados pelo autor. O primeiro dimensiona uma ética distante dos valores cotidianos se configurando num conhecimento confuso acerca do comportamento moral do indivíduo em que uma minoria busca de vários modos obter o poder, ou seja, ocorre a valorização das ações individualistas dos seres humanos em detrimento de ações coletivas. O segundo momento identitário da ética já busca desenvolver uma resistência a essas ações individualistas e muitas vezes coercitivas. Já o terceiro momento é mais autêntico, pois visa constituir uma ética genuinamente voltada para os interesses coletivos da sociedade valorizando a ética como uma ciência investigativa teórico-prática, filosófica e aproximada dos fatos cotidianos e, por conseguinte, dos valores e comportamentos morais.

(c) Revista Digital de Biblioteconomia e Ciência da Informação,Campinas, v.7, n. 2, p. 76-101, jan./jun. 2010- ISSN: 1678-765X. 
A partir dessa breve caracterização identitária da ética podemos incluir o terceiro termo de nossa discussão que é a informação. De antemão uma pergunta nos inquieta: como essa caracterização identitária da ética pode influenciar no comportamento informacional da sociedade, seja nas questões cotidianas, seja nas profissionais? Inicialmente é pertinente algumas interpelações em torno da aplicação ética a fim de saber como lidar com a informação. Temos como base para essa aplicação identitária da ética algumas perguntas feitas por McGarry (1999, p. 173-174) que são as seguintes:

\footnotetext{
-Quando uma ação é moralmente correta?

-Há certas situações em que determinada ação seria correta?

-Devemos executar determinada ação mesmo sabendo que as conseqüências podem ser erradas?

-Devemos executar determinada ação correta se tivermos bons motivos para acreditar que os resultados serão prejudiciais?

-Devemos executar uma ação aparentemente incorreta se acreditarmos que possa ter conseqüências desejáveis?
}

Diante dessas perguntas devemos levar em consideração dois fatores que envolvem a atuação de um profissional ou de um usuário com relação a informação. Os princípios éticos que fundamentam o uso dessa informação e as decisões tomadas ou não a partir desses princípios. Isto quer dizer que o profissional ou o usuário podem estabelecer um princípio ético ou podem ser gerenciados por um código de ética (principalmente o profissional) que é baseado num discurso, mas pode não cumprir em sua condição prática. Isso mostra uma desvinculação entre a idéia teórica da ética e sua aplicabilidade.

Com relação aos profissionais que trabalham com a informação, especialmente no que toca a proposição da Ciência da Informação é pertinente que levem em consideração estes dois fatores, pois a falta de compreensão dos princípios éticos ou sua má vontade podem interferir sensivelmente em uma atuação profissional satisfatória aos olhos do usuário. Para alguns o importante é o resultado, isto é, se o profissional cumpre sua função organizacional, de disseminação e acesso ao conteúdo referente à sua unidade de informação e o usuário faz uso indevido do material o profissional não tem responsabilidade alguma cabendo apenas ao usuário arcar com os prejuízos. Compreendemos que deva existir uma conexão estreita entre os pressupostos éticos e sua aplicação. Obviamente que o profissional tem por função primordial organizar, disseminar e tornar acessível, mas não podemos esquecer que toda informação tem um valor, seja ele material, abstrato, moral, social ou cultural implicando dizer que o 
profissional deve atuar contribuindo para a formação do seu usuário através de interações e orientações sobre o material mais adequado a ser utilizado. ${ }^{7}$

Isso não quer dizer que o profissional seja culpado no caso de um mau uso do usuário sobre um determinado conteúdo fornecido, mas o primeiro pode buscar desenvolver uma interação com o segundo, visando oferecer um serviço de maior qualidade. Este tipo de ação favorece maior contigüidade entre os pressupostos éticos e sua tomada de decisões deixando o profissional mais consciente de sua ação e contribuição. Dessa maneira, atentamos para a importância de eleger um objeto mais específico para que possamos compreender as concepções teóricas e de aplicabilidade da ética. Neste caso elencamos a Biblioteconomia para uma análise ética, tendo como suporte documental de referência o código de ética do bibliotecário que é o regente teórico e indicativo das ações do bibliotecário.

\section{A ÉTICA PROFISSIONAL NA BIBLIOTECONOMIA BRASILEIRA: UMA ANÁLISE SOBRE O CÓDIGO DE ÉTICA DO BIBLIOTECÁRIO}

A ética é um pressuposto científico-filosófico que merece destaque nos debates sobre atuação profissional a fim de saber se as concepções éticas que são apregoadas nos códigos estão sendo respeitadas e aplicadas a contento pelos profissionais. Por isso, percebemos ser necessário analisar o código de ética do bibliotecário e fazer um paralelo sobre a sua aplicabilidade pelo bibliotecário.

Logicamente que aqui não estaremos caracterizando de forma unitária os profissionais, mas sim a conjuntura nacional de relação entre o que afirma o código de ética e o nível de contemplação deste código pelo bibliotecário. Também é de fundamental importância saber sobre a qualidade de elaboração do código verificando se este vem levando em consideração a sua clareza, objetividade e o seu posicionamento diante dos fatos morais, cotidianos e profissionais que permeiam a sociedade brasileira, mais especificamente dos usuários. Seguiremos para efeito de análise os tópicos que compõem o código de ética do bibliotecário que são os seguintes: Objetivos, Deveres e Obrigações, Proibições,

\footnotetext{
${ }^{7}$ A ação freqüente do estudo de usuários e da educação de usuários pode ser uma forma efetiva de aproximar o profissional do usuário e de estabelecer o melhor fornecimento e uso de um determinado conteúdo, respectivamente. Agora, obviamente que o papel do profissional é orientar/indicar a melhor forma de utilização do conteúdo e não arbitrar sobre como deve o usuário proceder, sendo de responsabilidade do segundo eleger a sua maneira de como utilizar o material que dispõe.
} 
Infrações disciplinares e penalidades, Aplicações de sanções, Honorários profissionais, Abrangência do Código, Modificação do Código e Vigência do Código. ${ }^{8}$

Este código é referente à resolução no 42 do Conselho Federal de Biblioteconomia e foi publicado no Diário Oficial da União em sete de janeiro de dois mil e dois. Compõe-se de oito seções e vinte artigos que abrangem desde normas de conduta prescritivas, passando pelas sanções concernentes à desobediência dessas prescrições, até orientações quanto à remuneração e disposições gerais sobre o próprio código. (ARANALDI, 2005). Segundo Cuartas, Pessoa e Costa (2003), este código representa a quarta versão do código original que data da década de sessenta do século passado.

Com relação a primeira seção do código consta a seguinte afirmativa, segundo disposto no site do Conselho Federal de Biblioteconomia (CFB): “O Código de Ética Profissional tem por objetivo fixar normas de conduta para os profissionais em Biblioteconomia, quando no desempenho da profissão”. Entendemos que este objetivo contempla o primado básico de regência do código de ética que é ressaltar as implicações de uma boa conduta profissional. Porém, falar apenas da fixação de normas de conduta para o profissional é uma afirmação bastante geral e implícita, pois existem diversas formas de estabelecer normas para uma conduta do profissional. ${ }^{9}$ Por isso, consideramos pertinente a sugestão de que os objetivos poderiam ser especificados em geral e específicos em que o primeiro seria o que de fato foi estabelecido no código e os específicos seriam os dimensionamentos em partes do que foi falado no objetivo macro.

Por exemplo, poderíamos ter como objetivos específicos afirmações do tipo: Estabelecer normas relativas a atuação do profissional nos diversos tipos de biblioteca que atua; Fixar normas relativas a função técnica e sócio-humanista do bibliotecário; Estabelecer uma forma de conduta primando pela boa relação com o usuário, dentre outras, pois dessa forma o código consagraria questões específicas de atuação profissional que parecem ser tão obscuras na Biblioteconomia, como as que citamos.

\footnotetext{
${ }^{8}$ Estaremos disponibilizando o código de ética profissional do bibliotecário em anexo a fim de que o leitor possa acompanhar a análise juntamente com o código na íntegra.

${ }^{9}$ Essas formas precisam considerar a realidade mercadológica, social, política e econômica em que a área está inserida para que um código de conduta possua uma teorização bastante aproximada de ma contemplação prática das atividades mercadológicas e cotidianas.
}

(c) Revista Digital de Biblioteconomia e Ciência da Informação,Campinas, v.7, n. 2, p. 76-101, jan./jun. 2010- ISSN: 1678-765X. 
Marconi e Lakatos (1999, p. 103) confirmam a importância dos objetivos específicos quando dizem que "apresentam caráter mais concreto. Têm função intermediária e instrumental, permitindo, de um lado, atingir o objetivo geral e, de outro, aplicar este a situações particulares”. É possível perceber na fala das autoras que os objetivos específicos particularizam as idéias do objetivo geral e, acima de tudo, dão mais concretude aquilo que parece estar um tanto quanto obscuro ou demasiadamente geral. Com propostas afirmativas mais claras, particulares e objetivas (como as que disponibilizamos e outras não menos importantes) é possível que o bibliotecário possa adquirir um norte mais sólido no desenvolvimento de uma conduta ética.

No que se refere a seção II que se inicia com os deveres e obrigações do bibliotecário o código de ética está estipulado em 9 (nove) artigos. Inicialmente, versa sobre os deveres do bibliotecário subdivididos em 5 (cinco) tópicos. O primeiro destes tópicos diz que o bibliotecário deve "dignificar através de seus atos a profissão tendo em vista a elevação moral, ética e profissional da Classe”. Acreditamos que a trilogia moral, ética e atuação profissional é uma das chaves para o desenvolvimento institucional, tecnológico, social e humanístico de uma profissão. Porém, como argumentamos nos capítulos anteriores é preciso admitir que a moral possui diversas nuances que podem comprometer o caráter ético e profissional de uma área.

O segundo tópico diz que o bibliotecário deve "observar os ditames da Ciência e da técnica, servindo ao Poder Público, à Iniciativa Privada à Sociedade em geral”. Este, talvez, seja um dos tópicos mais polêmicos do código em virtude de envolver uma discussão acerca da profissão de bibliotecário. Seguir os padrões científicos a partir de seus valores éticos é de fundamental importância além do que o poder público, a iniciativa privada e a sociedade em geral são os três instrumentos de atuação profissional de qualquer área do conhecimento. Todavia, ocorre que a profissão de Biblioteconomia tem servido amplamente ao poder público e a iniciativa privada chegando a se estabelecer, em muitos casos, como subserviente a estes instrumentos. Almeida Júnior (1995, p. 9) é incisivo quando diz que “a Biblioteconomia não pode ser mais considerada como reprodutora da ideologia dominante, dos valores daqueles que detêm o poder”. Esta subserviência a ideologia dominante pode ser prejudicial para a Biblioteconomia relegando a um plano inferior as possibilidades de cumprimento do código de ética. É preciso oferecer novas marcas para a Biblioteconomia, como ações de cunho coletivo, 
desenvolvimento de projetos que satisfaçam inicialmente as necessidades da sociedade e tornem a Biblioteconomia eminentemente reconhecida e não projeções de promoções pessoais atrelada aos padrões governamentais. A Biblioteconomia necessita de ser um campo do conhecimento ideologicamente independente.

Por exemplo, a maioria das bibliotecas escolares e, em muitos casos, bibliotecas públicas municipais e estaduais não possuem um bibliotecário atuando e, alguns bibliotecários, são contratados para desenvolver um serviço extra de estudo e/ou educação de usuários, bem como de uma política de desenvolvimento de acervos recebendo um valor considerável para a realidade da área. Será que este tipo de ação parte de pressupostos éticos? Respeita o código de ética da área e a legislação bibliotecária? Será que este tipo de ação não promove uma profunda desordem na Biblioteconomia em termos de perspectivas de atuação profissional ocasionando um desrespeito entre os profissionais, uma individualização nas atividades em detrimento da coletividade institucional, política, social e cultural que rege a área? Será que é não é mais viável a classe lutar por concursos para as bibliotecas escolares e públicas, visando oferecer maior empregabilidade e possibilidades de atuação de seus profissionais?

Os dois tópicos subseqüentes afirmam que o bibliotecário deve "respeitar leis e normas estabelecidas para o exercício da profissão" e "respeitar as atividades de seus colegas e de outros profissionais”. Inserimos a análise destes dois tópicos de forma conjunta, uma vez que o respeito a ambos dependem bastante da conjuntura profissional e mercadológica da área. Ora, se o mercado para o bibliotecário se apresenta confuso, sem muitas perspectivas e com baixas condições de trabalho, especialmente no que tange ao salário e valorização do profissional, as possibilidades do não cumprimento ou de um cumprimento parcial destes quesitos ganha uma proporção considerável.

O último tópico que afirma ser papel do bibliotecário "colaborar eficientemente com a Pátria, o Poder Público e a Cultura” está intrinsecamente concatenado ao segundo tópico que versa sobre servir ao poder público, privado e a sociedade, mas possui um adendo relevante: que a profissão de bibliotecário possui um cunho eminentemente cultural. Daí fica a pergunta: será que o bibliotecário tem cumprido este tópico do código de ética envidando suas atuações profissionais de forma a valorizar o potencial da profissão em torno das perspectivas culturais, sociais, educacionais e cotidianas? Ou será que o 
bibliotecário tem sido um mero reprodutor das idéias do Estado, sem mostrar o seu posicionamento e a sua importância no processo de promoção cultural e conscientização da população?

O terceiro artigo fala sobre o que cumpre ao bibliotecário levando em consideração o procedimento de atuação deste profissional através de uma perspectiva liberal, humanista e que respeite a instituição a qual está ligado, bem como o respeito aos colegas de profissão. Percebemos que neste artigo existe uma profunda contradição com relação ao discurso estabelecido no código de conduta e a prática profissional propriamente dita, especialmente em um ponto que diz “combater o exercício ilegal da profissão”. Infelizmente, é possível observar diversas práticas ilícitas na profissão, principalmente em bibliotecas escolares e públicas em que ambas, como já falamos, em muitos casos não dispõem de bibliotecário, mas a própria profissão se submete as condições impostas pelo Estado e pela iniciativa privada, limitando o seu poder de intervenção na sua atuação profissional e contribuição para com a sociedade.

Os artigos quarto e quinto evidenciam essencialmente os valores voltados para a coletividade profissional enfatizando a consideração, apreço e solidariedade entre os bibliotecários, assim também, como os profissionais não devem se furtar ao cumprimento do código no caso de um companheiro de profissão cometer algum ato que venha comprometer a imagem da profissão. Isto é, não podemos confundir a palavra respeito com a supervalorização dos valores emotivos/pessoais em detrimento dos valores profissionais. Entendemos que a trilogia consideração, apreço e solidariedade é crucial para uma prática coletiva da Biblioteconomia, mas o atual mercado biblioteconômico chega a ser tão competitivo que impera a idéia do individualismo em detrimento dos valores apregoados neste código de ética, o que enfraquece a força política e profissional da área.

Oliveira (1983) questiona que a profissão de bibliotecário carece ainda de valores como autoridade, consciência de classe, senso de progressão e competição, consideradas indispensáveis à identificação da Biblioteconomia como profissão. Isso implica dizer que a falta dessa consciência de classe é uma ferramenta que torna a profissão individualista, fruto dos interesses e vaidades pessoais, ou seja, a classe biblioteconômica pode buscar alternativas de mudanças mais amplas, através da expressão coletiva a fim de tornar a 
área notável e reconhecida no mercado e na sociedade, resultando em uma maior compatibilidade dos pressupostos éticos que regem a profissão e a atuação do bibliotecário.

O artigo sexto invoca uma conduta do bibliotecário com relação à área zelando pelo prestígio as entidades de Classe no sentido de promover uma atuação política e profissional coletiva, bem como colaborar com o processo de fiscalização das atividades profissionais. Este último ponto é pertinente de um comentário em virtude de que atualmente é perceptível a falta de uma atuação mais rígida dos órgãos de Classe da Biblioteconomia no tocante a função do profissional e a abertura do mercado para a área, haja vista que diversas instituições educacionais, culturais, empresariais, sejam elas públicas ou privadas não dispõem de um bibliotecário, o que se configura na idéia que já mencionamos sobre a subserviência da Biblioteconomia ao governo e iniciativa privada.

O artigo sétimo enfatiza a relação do profissional com o usuário verificando os pressupostos de respeito ao público, buscando envidar grande esforço para prestar um atendimento de qualidade que possa satisfazer suas necessidades informacionais, bem como orientação de pesquisa e normalização de trabalhos acadêmicos. Neste ponto, sentimos profunda falta de um esclarecimento mais preciso acerca de procedimentos pelos quais o bibliotecário pode desenvolver visando efetivar uma relação promissora com o usuário. Sugerimos que o código de ética possa estabelecer condições de conduta, tais como: “aplicar estudo de usuários sempre que possível observando as necessidades informacionais do público e a busca pelo oferecimento de serviços que possam satisfazer os usuários” e “desenvolver um processo de educação de usuários estimulando o público a utilizar a biblioteca ou centro de informação de forma eficiente e eficaz para as suas exigências”. Acreditamos que esses dois aspectos podem consagrar uma relação mais efetiva entre bibliotecário e usuário insuflando a valorização do profissional e da instituição, além do respeito mútuo. Como afirma Figueiredo (1994, p. 7) "os estudos de usuários são canais de comunicação que se abrem entre a biblioteca e a comunidade a qual ela serve”.

Os artigos oitavo e nono parecem ser um tanto quanto repetitivos. Aquele menciona o interesse do bibliotecário pelo bem público a fim de que possa com seus conhecimentos e experiências servir a coletividade, enquanto este versa sobre a dignificação moral e 
profissional no cargo, emprego ou função que exerce. Por mais que possa ter alguma peculiaridade, estes artigos ao que parecem estão contidos no texto que fala sobre os deveres do bibliotecário (artigo segundo).

A terceira seção do código menciona as proibições ao profissional no exercício da profissão, tendo como destaques a prática direta ou indireta que comprometam a imagem da profissão, nomear pessoas que não sejam habilitadas para atuar como bibliotecário, conceder certificados para pessoas que não preencham requisitos para exercer a profissão, valer-se de influência política para benefício próprio, fazer comentários difamatórios sobre a profissão, dentre outros aspectos. Podemos notificar nessa seção que existe uma consistência naquilo que é vedado ao bibliotecário fazer, haja vista que valoriza o papel do profissional como sendo genuinamente habilitado para desenvolver suas funções em detrimento de profissionais que não são bibliotecários, mas são indicados para desenvolver o papel deste profissional.

A seção IV fala das penalidades no caso do bibliotecário cometer infrações que infrinjam o código de ética. Podemos observar que o código vai estipulando penalidades desde as mais leves como a advertência confidencial até a cassação do registro profissional competindo aos CRB's a tarefa de estipular a penalidade. É preciso, porém, que os CRB's estejam constantemente fiscalizando as instituições e os bibliotecários, visando aproximar os órgãos de classe do profissional, pois com uma fiscalização deficitária e a escassez de um debate sobre os pressupostos éticos da profissão parece ser provável que o profissional não reconheça os meios para se respaldar de princípios éticos, pois é fundamental para uma profissão baseada em princípios éticos teóricos que sejam contemplados na prática e adequados à coletividade da área e o bem da sociedade dispor de um órgão de classe que promova as condições para uma tramitação ética da profissão.

A seção V afirma que "O Conselho Federal de Biblioteconomia deve baixar resolução estabelecendo normas para apuração das faltas e aplicação das sanções previstas neste Código”. Mais uma vez é preciso reconhecer a necessidade de um posicionamento ético, político e fiscalizador dos CRB's e CFB para que o profissional possa se sentir bem representado e ciente da atuação do Conselho.

(c) Revista Digital de Biblioteconomia e Ciência da Informação,Campinas, v.7, n. 2, p. 76-101, jan./jun. 2010- ISSN: 1678-765X. 
A seção VI estipula os honorários profissionais afirmando em seus artigos 15 (quinze) e 16 (dezesseis) que "O bibliotecário deve exigir, por seu trabalho, remuneração justa e proporcional às atividades exercidas” e “O bibliotecário não deve oferecer ou disputar serviços profissionais, mediante aviltamento de honorários ou em concorrência desleal”. Concordamos que o bibliotecário é responsável pela negociação salarial, mas normalmente não consegue se responsabilizar por uma negociação promissora nas suas condições de trabalho. Dessa forma, o bibliotecário precisa constantemente da intervenção fiscalizatória dos CRB’s, visando dar um respaldo mais efetivo para o bibliotecário diante da instituição. Um conselho que atua de modo limitado e quase inoperante provavelmente irá causar uma desvalorização do profissional no mercado, seja em termos salariais, seja em termos de importância na atuação profissional.

As seções VII, VIII e IX atestam a institucionalidade do código através do CFB, sendo que a primeira mostra a abrangência do código afirmando que “As normas deste Código aplicam-se às pessoas físicas e jurídicas que exerçam as atividades profissionais de Biblioteconomia”, enquanto a segunda alerta sobre a modificação do código dizendo que “Qualquer modificação deste Código somente pode ser feita pelo Conselho Federal de Biblioteconomia, mediante proposta de Conselho Regional ou de Conselheiro Federal” e, finalmente, a terceira fala sobre a vigência do código orientando que “O presente Código entra em vigor em todo o Território Nacional, a partir de sua publicação, revogadas as disposições em contrário”.

Diante desta análise sobre o código de ética do bibliotecário, consideramos conveniente desmistificar algumas “presunções terminológicas” em que os termos código de ética e código de conduta profissional diferem em seu caráter filosófico e jurídico. É um código de conduta que prescreve como agir, sujeitando os infratores a penalidades previstas em lei no caso de transgressão às prescrições estabelecidas. Dessa forma, a denominação 'Código de Ética' não parece ser mais adequada para a realidade de uma conduta profissional institucionalmente recomendada ${ }^{10}$. Para ser mais claro expomos o argumento de Aranalde (2005) quando considera que seria mais adequada a formação de uma

\footnotetext{
${ }^{10}$ Como explicamos no primeiro capítulo deste artigo, a ética visa explicar uma determinada realidade cotidiana e moral dos fatos de modo a orientar a sociedade como desenvolver as ações mais coerentes para a coletividade. Isto implica dizer que não é um papel da ética e nem de um código de ética punir ou proibir ações, mas apenas avaliar e recomendar as ações mais cabíveis. Por isso, acreditamos ser mais conveniente denominar o código de ética do bibliotecário de código de conduta profissional do bibliotecário, já que o código em questão aplica punições e proibições, o que não implica numa função dos estudos éticos e de um código de ética.
} 
comissão de ética para avaliar atitudes não condizentes com a dignidade da profissão. Essa comissão poderia avaliar a perspectiva ética de ações passíveis de desaprovação ou censura e chamar o responsável por elas a dar boas razões para tê-las executado. Mas se for preferível a elaboração de um conjunto de prescrições previamente estabelecidas, então a denominação mais coerente para ele seria Código de Conduta Profissional e não Código de Ética.

Portanto, acreditamos que o código de ética do bibliotecário possui características eminentemente gerais e que, em alguns pontos, precisam ser especificadas, como propomos. É possível perceber também que muito do que se propõe no código de ética não é cumprido pela Classe biblioteconômica, sendo preciso uma reelaboração do código, mas principalmente uma reformulação daqueles que regem institucionalmente o código. É pertinente trazer o debate sobre o código de conduta profissional para as universidades, congressos e no cotidiano do bibliotecário para que a classe perceba a necessidade de se basear por pressupostos éticos que podem fortalecer a coletividade da área.

\section{CONSIDERAÇÕES FINAIS}

Este trabalho abordou a ética em seus níveis conceituais, do objeto e do campo de estudo verificando que não é fácil estabelecer uma definição de ética, ainda mais que seja aceita universalmente. Foi possível comprovar a variação das correntes éticas nos mais diversos períodos históricos dificultando ainda mais uma compreensão mais precisa sobre o termo. Outro ponto de grande importância é o princípio de que muito se fala acerca da ética, mas pouco se aplica ou se compreende de fato, isto é, a ética ganhou uma conotação pejorativa e vaga perdendo boa parte do seu sentido. Salientando que a reconstrução de um sentido para a ética perpassa diretamente pelo seu entendimento como um pressuposto político, filosófico e científico.

A partir da concepção política, filosófica e científica da ética é possível verificar com um pouco mais de clareza as suas características identitárias, bem como reconhecer como essa “identidade da ética” se posiciona informacionalmente. A ética não pode prescindir de explicar questões relacionadas à política e ao cotidiano, pois dessa forma poderá se inserir efetivamente no campo das explicações dos comportamentos morais da humanidade. No presente trabalho destacamos a corrente historicista da ética, pois é de 
grande importância para compreender os momentos históricos que caracterizam a percepção ética nas sociedades, suas diferenciações, semelhanças, peculiaridades, enfim, possibilita uma precisão maior na caracterização identitária da ética.

Devemos entender que a ética não deve ser um pressuposto distante da realidade social, política, econômica, cultural e educacional que nos cerca, pois, do contrário, não poderá se desenvolver como um indicativo informacional, haja vista que é muito mais conveniente para muitos profissionais criarem juízos morais que sejam convenientes num determinado momento para satisfazer suas “convicções profissionais/pessoais” em detrimento de uma coletividade.

Com relação ao código de ética do bibliotecário, entendemos que foi necessário empreender uma avaliação geral de cunho metodológico, reflexivo e conteudístico sobre a realidade apresentada no documento para sugerir transformações. Podemos dizer, em linhas gerais, que o código de conduta profissional da Biblioteconomia abrange o exercício das funções de bibliotecário pautadas na responsabilidade, no respeito e na dignidade.

Consideramos conveniente propor alguns indicativos para aprimorar o conteúdo do código. Mas o principal fato que queremos atestar é que existe certo distanciamento no pressuposto teórico estabelecido no código e sua contemplação prática. É de crucial importância a classe bibliotecária debater e auxiliar numa reconstrução coletiva fixando normas e recomendações que sejam o mais adequado possível as necessidades da profissão, principalmente em virtude das constantes mudanças que a área vem atravessando, especialmente no tocante as tecnologias.

O presente trabalho procurou desenvolver uma análise do Código de Ética Profissional do Bibliotecário, considerando suas perspectivas, delimitações e limitações constituindo algumas sugestões e concluindo que, em caso de atitudes não condizentes com a dignidade da profissão, seria mais adequado uma Comissão de Ética, constituída para avaliar ações que aparentemente não se enquadrem num Código de Conduta Profissional, pois é preciso uma fiscalização mais efetiva dos CRB's para saber da adequação do código a profissão. Por isso, uma comissão específica para cuidar desta situação seria de 
grande valia para a valorização de pressupostos éticos na Biblioteconomia brasileira desde a formação acadêmica até as práticas profissionais.

Finalmente, apontamos que é preciso uma reformulação do código e que muito do que se tem apregoado pelo código de ética não tem sido cumprido nas práticas profissionais e cotidianas do bibliotecário como foi possível verificar nos exemplos expostos relativos às áreas profissionais de biblioteca escolar e pública, bem como da ampla individualidade do profissional em detrimento da coletividade da área e ainda acerca da relação entre bibliotecário e usuário.

\section{REFERÊNCIAS}

ALMEIDA JÚNIOR, O. F. Biblioteca pública: ambiguidade, conformismo e ação guerrilheira do bibliotecário. São Paulo: APB, 1995. 12p.

ARANALDE, M. M. A questão ética na atuação do profissional bibliotecário. Revista Em Questão, Porto Alegre, v. 11, n. 32, p. 337-368 jul./dez. 2005. Disponível em: $<$ http://www.seer.ufrgs.br/index.php/EmQuestao/article/viewArticle> Acesso em: 25 abr. 2009.

ARISTÓTELES. Ética a Nicômaco. Bauru: EDIPRO, 2002. 287p.

BARROCO, M. L. S. Ética: fundamentos sócio-históricos. São Paulo: Cortez, 2008. 245p.

BOGO, A. Identidade e luta de classes. São Paulo: Expressão Popular, 2008. 264p.

CASTELLS, M. O poder da identidade. São Paulo: Paz e Terra, 2002. v. 2.

CONSELHO FEDERAL DE BIBLIOTECONOMIA. Código de ética profissional. Disponível em: www.cfb.org.br. Acesso em: 25 abr. 2009.

CUARTAS, E.; PESSOA, M. L.; COSTA, C. Ética profissional do bibliotecário: 15 anos depois. [Em anexo: Código de Ética Profissional do Bibliotecário, resolução CFB nº 42 publicada do D. O. U. de 7 jan. 2002]. Biblos: revista do Departamento de Biblioteconomia e História, Rio Grande do Sul, v. 15, p. 195-209, 2003.

FIGUEIREDO, N. M. de. Estudos de uso e usuários da informação. Brasília: IBICT, 1994. 154p.

HEGEL, G. W. F. Fenomenologia do espírito. 3. ed. Petrópolis: Vozes, 1997.

KANT, I. A metafísica dos costumes. Bauru: Edipro, 2003. 
RODRIGUES, M. A. B. A determinação do momento ideal na ontologia de Georg Lucáks. 1990. Dissertação (Mestrado) - Pontifícia Universidade Católica de São Paulo, São Paulo, 1990.

MARCONI, M. A.; LAKATOS, E. M. Metodologia do trabalho científico. 6. ed. São Paulo: Atlas, 1999. 219p.

MCGARRY, K. O contexto dinâmico da informação: uma análise introdutória. Brasília: Briquet de Lemos/Livros, 1999. 206p.

OLIVEIRA, Z. C. P. O bibliotecário e sua auto-imagem. São Paulo: Pioneira, 1983. 98p.

SILVA, T. T. (Org.). Identidade e diferença: a perspectiva dos estudos culturais. Petrópolis: Vozes, 2000. 133p.

VASQUEZ, A. S. Ética. 10. ed. Rio de Janeiro: Civilização Brasileira, 1987. 267p.

Recebido em: 23/06/2009

Aceito para publicação em: jul/2009 